\title{
The Poetic Interpretation of Binary Opposition in the Structure of Myth
}

\author{
Z. A. Aimukhambet ${ }^{1}$, A. Abdilmanatkyzy ${ }^{2}$, K. Baitanasova ${ }^{3}$, A. Seiputanova ${ }^{4}$, \\ K. Kurmambayeva ${ }^{5}$ \\ ${ }^{1,2,3}$ L. N. Gumilyov Eurasian National University, Kazakhstan, Astana, Almaty district, K. \\ Munaytpasov street 5. \\ ${ }^{4}$ Sarsen Amanzholov East State University, Kazakhstan, East Kazakhstan region, Ust- \\ Kamenogorsk, 34 Tridtsatoy Gvardeiskoy Divizii street. \\ ${ }^{5}$ Semey State University named after Shakarim, Kazakhstan, Semey, zoa Glinka street. \\ Email:asemgul_abdilmanatkyzy@mail.ru
}

Received February 23, 2017; Revised April 24, 2017; Accepted April 30, 2017; Published May 7, 2017.

\begin{abstract}
The article deals with the poetic nature of binary opposition in the mythology of literature. The structural method played an important role in revealing the nature of binary opposition in the structure of myth. The introduction of the article includes the theoretical significance of this method and the fact that the oppositional character of mythical worldview was the basis of dialectical development. The mythological motives and personages characterize the development of life, forming an opposition pair. The examples on the fact that oppositional pairs of mythical motives and characters constitute binary-dyadic integrity by complementing each other are represented. The controversial double forms of the dyad in mythical knowledge towards the paired phenomena and concepts is analyzed with mythical narration and concluded on the basis of scientists-mythologists' conclusions. The nature of phenomena and concepts between the dyad Chaos-Space and the opposition life-death are regarded in literary aspect and in the framework of the cultural-historical analysis. The idea about the important role of the mythical "binary-dyadic" structure in presenting the conflictive nature of a man in the world and national literature has been formulated. Interpretation of mythological thinking in poetics is given through motive, struggle and artistic images. Interpretation of binary opposition in poetic knowledge in the structure of myth is analyzed with references to some literary works.
\end{abstract}

Keywords: myth, binary opposition, structuralism, dyadic structure, chaos, space, good, evil, antithesis, Anima, Animus, oxymoron, antonym, protagonist, antagonist, historical consciousness, artistic knowledge, poetics.

\section{Introduction}

The initial human outlook is based on the knowledge and understanding of the nature of contradictions. Peculiarity of binary opposition in the nature of myth, which is an ancient worldview, reminds the unity of opposites, ensuring the legitimacy of the struggle of the law. It is known that binary opposition (Lat Binarius - double, consisting of two parts) in the aspect of linguistics is a type of communication in the framework of the semiotic system, which makes sense only in connection with a particular sign in opposition to another sign (Encyclopedia of culture and society). Giving a simple example, we know that the meaning of the words "good",

(c) AesthetixMS 2016. This Open Access article is published under a Creative Commons Attribution Non-Commercial 4.0 International License (http://creativecommons.org/licenses/by-nc/4.o/), which permits non-commercial re-use, distribution, and reproduction in any medium, provided the original work is properly cited. For citation use the DOI. For commercial re-use, please contact editor@rupkatha.com. 
"near", "hard", "sweet” (water), “white” as a linguistic sign determine the words "evil”, "far", "soft”, "salty", "black".

Since the second half of the XX century, the notion that any phenomenon in science has a certain structure, based on F. de Sossyur's concept, prevailed. Hence there was structural linguistics. Studying the structure of language, F. de Sossyur identified the synchronic order of inner connection between the characters which are its elements. According to Sossyur, the language elements function in opposition system which distinguishes them from each other and connect with each other. The meaning is the result of connection of components of this system or structure (F. de Saussure Course in General Linguistics). In addition, Sossyur considers language as a functional difference and opposition system. The whole mechanism is formed on the opposition, the phonetic and conceptual differences in addition to it. Of course, we cannot deny the validity of this conclusion.

Studying the phonetic structure Roman Jacobson, whose idea was developed by Sossyur further, said that the feature of phonetics is in its dualistic, i.e. binary nature. Agreeing with Jacobson's opinion we can say that all the phonemes create a pair, opposed to each other, in any language. For example: vowel=consonant, voiceless=voiced, soft=strong. Language signs and events are the result of human relationships with each other and a pair defining the qualities, properties and form of each other.

In the theory of structuralism binary opposition will become the main category, characterized by life principles of nature and culture. French structuralists, including ethnologist and anthropologist Claude Levi-Strauss explain that the structural model of linguistics and anthropology are similar, taking the idea of binary opposition of structural linguistics. And these models start with unconsciousness that is the concept which exists in the structure of the human mind from the very beginning. According to Levi-Strauss, the language is a picture of national culture, but its structure is not accepted in the spoken language. Language is a phenomenon that generates the internal structure itself. If you take Levi-Strauss' conclusion, we can compare myth with the language, the myth also has a structural nature which is not accepted by speakers (unconscious structure) (Lévi-Strauss, 2006).

To determine the unconscious structure we need to understand the culture, mentality and spirit of the nation and to determine the binary opposition. Levi-Strauss considers the binary opposition as a mytheme, which is a key part of thinking. Indeed, the ancient form of desire to recognize the world is in this mytheme. From the point of view of literary and cultural analysis, "Binary opposition is a universal means to understand the world, widely used in the XX century. There is binary opposition in any way of describing the worldview, and they differ in universal character: life/death; fortune/misfortune; right/left; good/bad; near/far; past/future; here/there. One side of this opposition is characterized as positive and the other as negative" (Rudnev, n.d.).

Myth pays special attention to the contradictions in the structure of the world as a whole, as one of the forms of the ancient worldview and historical consciousness. Binary-dyadic structure described by structuralists occupies a special place in the mythological perception of the world and is mentioned as the source of nature, mechanism of development and as the driving force. By studying the nature of binary opposition in the mythical knowledge we draw attention to their meaning. 


\section{Research materials and methods}

The methods as a cultural-historical, historical-typological, analysis, synthesis, comparativehistorical, structuralistic and hermeneutical method are used in the study. As the research material we use the motives of Egyptian, Chinese and Turkic mythologies, the Kazakh folk tale "Good and Evil", the eastern fairy tale "Mart and Namart", M. Zhumabaev's poem "The Prophet" and the story "Sholpan's sin", T. Abdikov's "Right hand" and "Battlefield of sanity", Hermann Hesse's "Steppenwolf”, E. T. A. Hoffmann's “The Devil's elixirs”. In the analysis of the binary structure of folklore and artistic works, presenting the nature of the work and characters are carried out by comparison and discussion. The conflict between Geb and Nut in Egyptian mythology, the struggle between Horus and Seth, the concept of Yin and Yang in Chinese mythology as the motives, representing the basis and legitimacy of the natural dyads have been taken into account. The examples of the struggle between good and evil, white and black on the basis of contradictions and struggles in the mythological stories, taken as the basis of the work of art, and the interpretation with the help of new plots and motives are given from the abovementioned works of art. The nature of the characters with complex nature in T. Abdikov's, Hermann Hesse's, E. T. Hoffmann's literary and artistic works are determined by comparative analyzes. Division of one person into two parts and struggle with himself in T. Abdikov's story "Right hand" (Alma and her right hand) and "Battlefield of sanity" (the patient and a strange friend) have been analyzed. Division of a character into two and becoming an antagonist/protagonist person in T. Abdikov's story "Battlefield of sanity" is compared with the image of Harry Haller in Hermann Hesse's "Steppenwolf”, E. T. A. Hoffmann's "The Devil's elixirs”, O. Wilde's “The Picture of Dorian Gray”, H. C. Andersen's “The Shadow”, F. Kafka's “The Metamorphosis" are noted along with the analyzed works in accordance with the culturalhistorical and historical-comparative method.

\section{Results of the research}

The binary opposition in modern works of art originates from the system of mythical thinking has been proven in the analysis of the relationship of knowledge mythical and poetic thinking, guided theoretical research. The fact that the binary opposition in contemporary works originates from the system of mythical thinking has been proved, guided by theoretical studies, in particular, the works of the scholars like F. Sossur, C. Levi-Strauss, F. Nietzsche, D. Norman, V. Naidysh, A. Maslov and others, in the course of analyzing the continuity of mythical cognition and poetic thinking.The motives of mythical consciousness show that the dyadic unity of concepts and phenomena of binary-oppositional character is the basis of their relationship with each other.

Also we analyze the binary-oppositional structure, allocating protagonist- antagonist person. It is the basis for the division of a character into two parts. The description of the problem of duality in the literature through the examples of world and national literature is reviewed.

It has been proved that the binary opposition in the literary space in the mythical structure is the basis for allocation of the protagonist/antagonist characters. And the struggle of the opposites goes on the nature of the character, "separated" persons, opens the way for the struggle between man and his shadow and creates a "double" of the image (twice). All this is explained on the basis of specific examples.

With the artistic and aesthetic point of view, the important role of the mythical-binary structure in human purpose and description of the struggle between good and evil is concluded. 


\section{Discussion}

\section{Dual and contradictory nature of the dyad in a mythical knowledge}

"On the basis of any myth there is an opposition, any myth starts with a binary opposition, for example: life and death, heaven and earth, day and night, right and left, up and down, sacred and miserable, raw and ripe, black and white, and etc. Expansion of the myth content is formed as a result of the gradual elimination of this fundamental contradiction. For this purpose mediation formed mediator of intermediate elements that determines the pole of mythical-creative oppositions is formed" says V. Naydysh (Naidysh 2004, p.456).

We can see the dyadic form of any motive of myth as the ancient worldview. It includes chaosspace, Heaven - earth, day - night, good - evil, black - white. These twin concepts are not only closely related to each other, but also have mutually contradictory character.

Initially the disorderly chaos, and then a space, as the order and harmony placed against it are said in the myths about the creation of the world. Further a contradictory and entire pair is the sky and the earth.

Thus, according to sayings in the mythical knowledge the world is put in order as a result of conflicting connection chaos-space. In the mythology of ancient Egypt God Atum's creating Shu and Tefnut from itself, and the birth of children of this pair, Geb (male) and Nut (woman) is described. Geb is characterized as the earth, and Nut as the sky:

"Geb and Nut loved each other so much that they were born in an embrace. Thus, initially, they had been pasted to each other. Their children were born like stars. Geb and Nut quarreled one day. The cause of the conflict was that Nut always swallowed their children. Geb was angry with this. Heaven and earth have lost peace. The god of sun Ra told Shu to separate them. Shu lifts Nut upstairs and separated their hugs. Thus the sky is separated from the earth" (Zgurskaya 2014, 222).

Here Nut is described not only as a liquidator, but also as a creator (birth star). So he is the creator and destroyer of stars. Nut is a dyad of creator/liquidator in mythical consciousness. Separation of heaven and earth in the narration of myth is associated with the scandal between Geb and Nut.

In K.Yung's theory of archetypes Anima and Animus is explained by female (maternal) and male (paternal) archetypes. These two twin archetypes that complement each other, as well as the creatures with contradictory character. Discussing the oppositional character of nature on the mythical basis, the scientists once again confirm that this contrast is the basis for the development of the dialectic relation. In his reasoning on the mythical symbolism Dorothy Norman says:

"We constantly meet face to face with the opposites as life and death, heaven and earth, day and night, motherhood and fatherhood, past and future and what we have inside and opposite. Not only opposed pairs, as well as their endless ways of combinations puzzle us. Then we can only agree with this confusing combination and clearly look at them" (Norman 2005, 412).

In the mythology from Chaos-Space opposition to life-death many opposing concepts and phenomena are covered. In the example above, the heaven-earth is not only a binary-dyadic pair, but also the creation of an opposition. The opposition heaven-earth is depicted as Yin and Yang in Chinese mythology, Uranus and Gaia in Greek mythology, Geb and Nut in Egyptian mythology. 
As well as the endless battle of Shiv and Vishnu, Horus and Seth is a binary basis of the mythical worldview. If all the natural creation whether it is concrete or abstract creates the opposite couple, they occur as a result of this particular controversy.

The eternal struggle of black and white, good and bad, good and evil, generosity and cowardice in the mythical knowledge is depicted in the form of two characters, two rulers and two "gods", opposed to each other as we know from the myths of the world. A. A. Maslov writes

"The concept of Yin and Yang, opposite and complementing each other beginnings, covers all the cultural traditions from public administration and human relations to the rules of supply and self-regulation. They are also common in the complex system of relationships between man and the spiritual world" (Maslov 2006, p. 29).

The ancient Chinese describe these two principles as follows: Yan - sky, masculine, south, light, life, sun, odd number; Yin - earth, feminine, north, moon, darkness, night and even number.

In the Kazakh national folklore "Good and evil" or "Mart and Namart" ("Brave and coward") in the tales of the Eastern peoples, two characters with opposite nature go on a journey together. Good (Mart) pitied evil that had been left without a horse, and set him on his horse. After that Evil (Namart) deceives Good and leaves him on the road. This example shows that they have different ways. But their paths cross each time. After Evil's each bad behaviour, luck is always waiting for Good, because life itself is based on the struggle between Good and Evil. Since these concepts are contradictory, Good and Evil act so as they are named in a fairy tale.

Describing the sources of two beginnings of the world as good and evil, philosophers have proposed different concepts, paying attention to the mythical worldview. It is known that these concepts are currently looking for "seed" from the myths, legends and fairy tales. In the 725 of the XIX century, as a result of these investigations, German philosopher Friedrich Nietzsche proposed the concept of "Appolo" and "Dionysus" (Nietzsche 2006). Both Apollo and Dionysus are the characters of Greek myth and Zeus, the god of lightning is considered their father. According to Nietzsche's statement western thinkers Plutarch and Thomas Mun give their views. They systematize different qualities in the nature of the sun god Apollo and Dionysus the god of wine, which are different from each other, and define their opposite way of life. Heaven and earth, black and white, darkness and light, hot and cold, day and night, height and bottom, north and south, east and west, good and evil, angel and demon in the mythical knowledge create the pairs opposed to each other, but inseparable from each other. Although they are fighting among themselves, they cannot function without each other. From a philosophical point of view, we know that one of the basic laws of dialectics is the unity and law of struggle. According to this law, it is known that there are contradictions of phenomenon and processes on the basis of development. These contradictions will become the cornerstone of development. Unity and struggle of opposites are the source of movement and the whole being. Famous German philosopher Hegel made the analysis of contradiction studies from the dialectical point of view. The contrast shows the conventional contrast of opposite phenomenon, things and concepts. There are moments where all the contradictions go on compromises. The contradictions, namely, the relations between the two concept of one reality is the basis of development, and great Abai's words as "Where is the struggle between love and hate//My poor heart is frozen" reflects that. In other words, the field of struggle of opposites, which is the main mechanism of life and development, is living space and the spiritual world. This law of development is manifested in different ways of the image of art works and in stylistic form, creating an artistic picture of life. It is necessary to understand the meaning of the stylistic forms in fiction samples like oxymoron, antonym and antithesis as an artistic way. 


\section{Picture binary-dyadic structure of the myth in artistic knowledge}

The opposite phenomenon and concepts are characterized by the terms as antonym, antithesis, oxymoron in the linguistic and artistic worldview. These philological terms paved the way for the formation of artistic methods in the poetic system of thinking. In determining the nature of the art binary-oppositional structure standing out with dyadic meaning, it is necessary to pay attention to their mythtectonics.

Language and art of the system of opposing concepts exist in the structure of any work of art. The struggle, characteristic to art and culture of the ancient world, is based on such differences. As an example, first we can say about the classification of the protagonist//antagonist personalities in Greek dramaturgy.

"Protagonist is one of the three actors of ancient Greek tragedies, performs the title role (the second actor deuteragonist, the third one - tritagonist). Protagonist in new literature is an antihero, mainly in drama; antagonist - the main character which is opposed to him. Protagonist from the Greek word "protos"- first that comes from the word "agonistes", is translated as an actor" (Literary glossary). Protagonist, as a person acting from the face of the main character, mainly refers to the generosity and kindness, antagonist, on the contrary is an image of evil on the other side. Thus, maintaining binary-oppositional basis, the dyad of creation continues "to live" with his language and artistic nature. Nature of the opposition on the basis of nature is defined, classified and transferred to an individual in a work of art. As a linguistic phenomenon, oxymoron is a means of poetic text. In his publication "About Anna Akhmatova's poetry (stylistic models)" V.V.Vinogradov presents oxymoron as a symbol that "determines the nature of things, phenomena and signs" (Vinogradov 1976, p. 385).

Considering the structure of oxymoron "a small condensed phrase", Vinogradov draws attention to the expansion of its structure in the process of comparison. Having said that it can be a whole complex sentence, he analyzes the transformation of phraseology to an oxymoron as a result of semantic change. The author of the publication "Blok's Contrast poetics" L.N.Timofeev shows that the peculiarity of Blok's poetic knowledge is the description of contrast. The poet uses the oxymoron, antonym in the composition of epithet works, in the system of images, in scene development, in the themes of opposite nature, and notes the logical accumulation of language sometimes in the form of simple phrases and inner contemplation (Timofeev 1961, p. 48)

In the publication of another researcher L. A. Vvedenskaya "stylistic figures based on opposites" an oxymoron is considered not only one of the stylistic, but also the most effective means of art ... a combination of words that do not match with the viewpoint of logical thinking" (Vvedenskaya 1966, p. 128). The researcher gives great importance to the linguistic nature of oxymoron. Two words of antonymous opposite are taken as the components. In this case, "the first antonym is given as the determiner of the second word: old age in youth and old youth" (Vvedenskaya 1966, p. 128). In the theoretical definition an oxymoron is given by means of antithesis, akroteza, amfiteza, diazteza in the opposite meaning.

The method of antithesis is known from Akzhunis's famous monologue from the epic poem "Er Targyn”. According to foreign philologists' opinions about amfiteza and akroteza, representing semantic integrity, "the function of an antonym is not limited to opposite. Antonyms may signify other kinds of relationships without opposite semantics (method of amfiteza). Akroteza amplifies certain interrelated character, denying its opposite term" (Koryukina 2011, p. 310-311). It is obvious that the author implies the opposition link here.

As an example of akrateza we can give M.Zhumabayev's verse "Divinity": 
Darkness covered the west,

The sun had set, dawn hasn't come.

Evils, born at night, go so gloomy

They trample on the deity (Zhumabayev 2005, p. 41),

So begins the verse where the West is defined by the concept of night, darkness, and is portrayed as the source of all evil and villainy. Demonstrating the negative effects of the night which "bows not to God but to the devil" and "that burns the Bible, tramples the Koran", the poet notes the highness of the second term, the East. So he elevated the child of the sun with "white gold line", "lightening the whole land", up to the level of "a prophet". The light and radiance of the East dominated through the darkness of the West. Thus he denies "the night demons", "killer of the prophet" describing his negative actions. However, the child of the night in the West is "waiting for a prophet from the East". Here we see the mechanism of an opposition relationship between the two opposing concepts. The protagonist personality is the son of the sun in the East (the Prophet), the antagonist is the son of the night in the West.

And also, it is necessary to consider the term alogism pertaining to oxymoron. "Alogism is a stylistic device in the work of art. The stylistic or plot-compositional structures are formed by logical violation or removal of the link between the concepts in the works" (Krivonos 2008; Jung 2003).

\section{Function of isolating "dyad-heroes" of binary opposition in the mythical perception.}

If we pay attention to the above given definitions, we can see that all the ways of oppositional structure begins with the tectonics of binary structure on a natural basis. And this binaryoppositional structure serves to define dyadic images in fiction. The binary opposition from the struggle protagonist - antagonist of individuals to the division of the character's nature into two "is absorbed" in fiction and leads to the formation of dyad-characters by oxymoron, antithesa, antonym, amphiteza, acroteza. In the national literature the division of one character into two is found in M.Zhumabayuly's "Sholpan's sin", Zh.Aymauytuly's "Ghost", M.Auezov's "Beauty in mourning" in psychological analysis, and in O.Bokeykhan's "Devil's Bridge", A.Kekilbay's "The end of legend", T.Abdik's "Right hand", "Battlefield of sanity" and "Pedestal and life", M.Magauyn's "Kipchak girl"and "Zharmak" it is reflected in different forms.

In ancient Egyptian mythology the battlefield of Horus and Seth, "the glorious" characters in the space is transferred to a person's inner world in the works of art. It is an episode of transformation of binary opposition in the structure of myth. The characters in T. Abdik's stories "Right hand" and "Battlefield of sanity" are characterized with "split" personality. Remember the mysterious case in the psyche of an eighteen-year-old girl Alma whose right hand threatens her attack in the story "Right hand", told by the doctor. Image of Alma in the Kazakh literature can become an example of "different kinds of" creatures. The girl and her right hand against each other represent "a character divided into two".

This story is told in the form of narration by a doctor.

"At the end of March a girl of about seventeen was taken to us. Her parents told that she tried to strangle herself several times. She survived to people who had seen her at that moment. But the girl tells her story differently. She says: "This hand wants to kill me, it's not my hand, it attempts on my life" and shows her right hand. We call it the division of the inner personality into two parts. This is one of the types of psychopathology. That is, two different "living beings live in one body simultaneously or alternately". They are all unresolved mysteries of the brain" (Abdikuly 2012, p. 539). 
The narration of the doctor is the beginning of the plot of the story. Then the doctor takes the patient under his control and tries to find the cause of the disease.

The contradictory nature of the diadem-character in "Battlefield of sanity" is represented from psychological and philosophical point of view. In the story "Pedestal and life' this problem becomes even more difficult, and demonstrates the destiny of a man who had a blow of fate.

The epigraph to the novel "Battlefield of sanity", taken from the American writer Robert Penn Warren's words "You have to make good from bad, because there is nothing to do it from" seems to explain the meaning of binary opposition in nature from philosophical point of view. The content of the story reveals the meaning of the word.

The protagonist character (the patient aimed at the nobility) and the antagonist character (stranger sending letters) is one and the same person. All thoughts, actions, objectives are presented by the patient's diary, the stranger's thoughts and opinions are expressed by the letters. Thus, one person becomes two characters. The works of art in different forms show that two different forms and two directions are originated from the struggle of the mythological knowledge, and become the basis of human life. Archetypes of mythological cognition show this pattern through different forms, one of them is shadow. The shadow, which is an autonomous part of human existence, plays a key role in the reason of the character's division into two parts in the work of art.

The archetype of the shadow in the theory of Swiss K.G.Yung is responsible for the negative thoughts and behaviors, feelings and actions in human mind. The unconsciousness, said by Freud, corresponds with the archetype of the shadow. "Negative" sides i.e. covert harmful properties, actions developed insufficiently and the content of individual unconsciousness are explained using the shadow" (Jung 2003, p. 72). Thus, it is the cause of negative thoughts, feelings and actions in the mind and behavior, which are not approved by social environment. According to Jung's analysis, it reproduces animal instinct in a man. The shadow, which is characterized by psychodynamic contradictory, serves to open the second negative side of a main character.

In his works, the classic of world literature, famous German writer, composer and artist, raising the Romantic literature to a new level, Ernst Theodor Amadeus Hoffmann pays special attention to the difference between white and black, which is full of clash of dual feelings. The main theme of the writer, who is looking for the answer to the questions like where evil begins; who is a supporter of good, etc. is the battle between the two natures in a man. Hoffmann's "The Devil's elixirs", where the theme is the link between spirit and desire, the relationship between consciousness and unconsciousness in psychology, describes the conflict between priest Medard's two human natures. One of them tends to the kindness, God, purity and honesty, the latter tends to ambition, wealth and power and ready to do any harm and cruelty to get them. It shows that faith in God and love will lead a human to honesty, and devil will lead to evil and deceit (Hoffmann 2012).

Recognizing the shadow archetype as the beginning of a man's animal instinct, K. Jung explains that "the body is an animal, with the nature of the animal, which is a living system integrated with the instinct, the instinct of the beginning. To be with the shadow is to tell the instinct "yes", as well as to approve the scandalous trend in the depth of the heart" (Jung 2003, p. 35). Here the problem of the struggle between mind and body, spirit and lust are taken into account.

When it comes to binary opposition and artistic transformation of the notion of a dyadic unity, we can give examples from world literature. The source of metamorphosis, which has become a regular motive of fairy tales, is mythical variability. Changeability in myth, transition from one 
form to another indicates duality and struggle. Transformation of a person into an animal at night and into a human by day is found in the tales of Turkic and Slavic peoples. This transformation in the eastern stories dominates in the form of evil wizards or particular people with mysterious power. Division of a personality into two and their contradiction is given in Danish fairy writer Hans Christian Andersen's “The Shadow”.

Unity of binary opposition in the mythical knowledge in the work of the famous English writer of Irish origin Oscar Wilde's "The Picture of Dorian Gray", the Nobel Prize winner, German writer Hermann Hesse's "Steppenwolf”, Russian classic writer Fyodor Dostoevsky's "The Double”, German-language writer Franz Kafka's "The Metamorphosis”, Japanese writer and critic Edogawa Rampo's "The Monster in the dark" and other literary and artistic works based on the formation of diadem-characters and the description of the dynamics of human life contradictions in a man's inner world.

H. Hesse describes his hero Harry Haller as follows: "the dual nature of the steppe wolf - the wolf and human nature and its special and unique destiny" (Hesse 2007, p. 51). He also describes terrible condition and appearance of evil in the division into two: "All these people can hold a double soul, two living beings based on the divine and the diabolical principle, the paternal and maternal blood, propensity to happiness and suffering in their nature. All these qualities are mixed, face and turn to Harry human and wolf" (Hesse 2007, 55).

We can cite many examples from national literature based on the works in order to give shades in the art space, to describe the illegible history with the collision and to represent complex character. As the personality with black and white, good and evil in one body with a "double nature" we can call Alma (T. Abdik "Right hand"), the patient (T. Abdik "Battlefield of sanity"), Kipchak Khan Kobek's son, the stonecutter, who was carrying the cargo of national history and destiny, sculptor Sarzhan (M. Magauin "Kipchak girl") and others as a transformed reminiscence in poetic knowledge of mythical-binary opposition.

\section{Conclusion}

Thus, in the article we have tried to show that the binary opposition in mythology is the system from the mythological idea to artistic thinking based on the examples. Comparing the models of world literature and examples of national literature, we see that the ways of formation of contradictions are demonstrated by description in poetry and prose.

It is found that the human nature full of conflicts of double sense and the laws of nature in the works of poets and writers. Writers, who were looking for answers to the questions about the beginning of good and evil, overlook the struggle of opposites in a man. One of them tends to kindness, God, purity and honesty, the latter tends to ambition, wealth and power, and goes to the shamelessness and cruelty to get them. Humanistic goal in mythical knowledge and artistic space that originates from there becomes the basis of the struggle over darkness and evil. The binary opposition in myth-structure leads to a new artistic world, portraying the nature of conflict in the poetic knowledge.

The binary opposition in the mythical structure becomes the basis for allocation of protagonist/antagonist characters in literary space. And also the struggle of opposites is transferred to the character's nature and open the way for the creation of personalities "divided into two", the struggle between a man and his shadow, the "double" image.

Division of one character into two parts psychologically is the description of the law of life with contradictions and dialectical development with a hint or a hidden meaning. A character with a 
complex nature from the philosophical and aesthetic point is the result of creative research. Such characters in modern novels, stories and poems, which make readers think, appeared with new features. The triumph of good and fulfillment of the dream of mankind must begin with a man's defeating an evil in him. This principle is obvious in the analyzed works. The character from $\mathrm{T}$. Abdikov's story "Battlefield of sanity" is forced to kill himself for the good and humanity in the final part. Thus, the writer's humanistic position is determined. In the story "Right hand" the death of the character from his right hand is the action of human evil. With the help of this story about the right hand the writer gives his philosophical thoughts. The characters with a contradictory nature in the works of $\mathrm{H}$. Andersen, O. Wilde, H. Hesse, M. Zhumabaev, M. Auezov, M. Magauin are proof that the binary structure of ancient mythic cognition is used to raise contemporary actual problems. Thus, the mythical-binary structure plays a key role in studying human purposes, in describing the endless struggle between good and evil from artistic and aesthetic point of view.

\section{References:}

Abdikuly T. (2012). Mind flaming war. Almaty: Raritet, p. 616.

Encyclopedia of culture and society (Electronic resource). Retrieved 15.11.2016, from http://glossword.info/index.php/term/

F. de Saussure Course in General Linguistics. (1998). Moscow: Logos, pp. 19-21.

Hesse H. (2007). Steppenwolf (the first publication 1927 y.). St. Petersburg: Azbuka-klassika, p. 288.

Hoffmann E. T. A. (2012). The Devil's Elixirs (the first publication 1815 y.). Moscow: Astrel, VKT, p. 384.

Jung C.G. (2003). Psychology of the Unconscious. Moscow: Canon +, p. 400.

Krivonos V. S. (2008). "Oxymoron". Poetics: a dictionary of relevant terms and concepts [Head of scientific publications N. D. Tamarchenko]. Mscow: Publication Kulagina; Intrada, p. 358.

Koryukina E. S. (2011). Rhetorical possibilities of lexical antonyms. Herald of the Lobachevsky State University of Nizhni Novgorod, 6-2, 309-313.

Lévi-Strauss C. (2006). Mythologiques: The Raw and the Cooked. Moscow: «Fluid» publishing house, p. 399.

Literary glossary. Internet resources. Retrieved 15.11.2016, from http://www.litdic.ru/protagonist/

Maslov A.A. (2006). China: taming the dragons. Spiritual quest and sacred ecstasy. Moscow: Aleteia: Cultural center "New Acropolis", p. 480.

Naidysh V.M. (2004). The philosophy of mythology. XIX - the beginning of XXI century. Moscow: Alpha M, p. 544

Norman D. (2005). Symbolism in the mythology. In the book: Mythology: structure and symbols. Almaty: Zhazushy, p. 568.

Nietzsche F. (2006). Complete works. In 13 volumes. Volume 1. Part 1. The Birth of Tragedy. Heritage 18691873 years. Moscow: The cultural revolution, p. 416

Rudnev V. (n.d.). The dictionary of culture of the twentieth century (Electronic resource). Retrieved 15.11.2016, from http://slovar.lib.ru/dictionary/binaroppozicija.htm (time of review: 24.12.2015)

Timofeev L. (1961). the poetics of contrast in Blok. Russian literature, 3, 98 - 107

Zhumabayev M. (2005). Multivolume collected works. 1 volume. Almaty: Zhazushy, p. 208.

Zgurskaya M.P. (2014). Mysteries of history. Ancient Egypt Directmedia, p. 380.

Vinogradov V.V. (1976). About the poetry of Anna Akhmatova (Stilizacia studies). The poetics of Russian literature. Moscow: Nauka, p. 511.

Vvedenskaya L. A. (1966). Stylistic figures based on antonyms. Academic notes of the Kursk and Belgorod pedagogical institutes. Short essays on the Russian language. V. XXV. 2 edition. Kursk: AST 